\title{
Hydroxychloroquine Treatment may Benefit Nucleic Acid Testing of SARS-CoV-2 Turning Negative in Critically ill COVID-19 Patients: Report of 3 Cases
}

\author{
Chunyan Wei ${ }^{1(\mathbb{D})}$, Yang Bai ${ }^{1(\mathbb{D})}$, Zhiyao He ${ }^{1(\mathbb{D})}$, Xiaofan Fei ${ }^{1, *(\mathbb{D})}$ \\ 1 Department of Pharmacy, West China Hospital, Sichuan University, Chengdu 610041, Sichuan, P.R. China \\ * Correspondence: $1145342867 @ q q . c o m ;$
}

Scopus Author ID 57202187834

Received: 22.05.2020; Revised: 26.06.2020; Accepted: 28.06.2020; Published: 3.07.2020

\begin{abstract}
Since the outbreak of coronavirus disease 2019(COVID-19), hundreds of thousands of people have been infected. After fighting with the virus for two months, the epidemic in China is well controlled. However, many countries are still struggling with the coronavirus. Effective anti-viral drugs are important to reverse the patient's condition, especially for critically ill patients. We report 3 cases of using hydroxychloroquine in the treatment of critically ill COVID-19 patients. Results show that hydroxychloroquine treatment may benefit nucleic acid testing, turning negative in these patients.
\end{abstract}

Keywords: Hydroxychloroquine; critically ill; COVID-19; nucleic acid testing.

(c) 2020 by the authors. This article is an open-access article distributed under the terms and conditions of the Creative Commons Attribution (CC BY) license (https://creativecommons.org/licenses/by/4.0/).

\section{Introduction}

Since the coronavirus disease 2019 (COVID-19) first occurred in China at the end of 2019 , it has spread rapidly around the world, with more than $2,800,000$ people infected. The World Health Organization made the assessment that COVID-19 can be characterized as a pandemic [1]. At present, no effective anti-viral drugs have been found to treat severe acute respiratory syndrome coronavirus $2(\mathrm{SARS}-\mathrm{CoV}-2)$, which causes this disease. Researchers in China are trying to find effective drugs from existing ones [2-6]. The severe acute respiratory syndrome coronavirus (SARS-CoV), Middle East respiratory syndrome coronavirus (MERS$\mathrm{CoV}$ ), and SARS-CoV-2 all belong to the $\beta$-coronavirus genus [7]. Chinese clinicians speculate that the drugs which are effective against SARS-CoV or MARS-CoV may also be effective against SARS-CoV-2. Chloroquine is an antimalarial drug, which is structurally modified according to quinine. It is also resistant to amoeba and is used in autoimmune diseases. In recent years, chloroquine has been proved to have a broad-spectrum anti-viral effect[8-10]. In 2005, Vincent reported that chloroquine is a potent inhibitor of SARS-CoV infection and spread in vitro [11]. Studies in China have also shown that remdesivir and chloroquine can effectively inhibit SARS-CoV-2 [12]. At present, fifteen studies have been registered in the Chinese Clinical Trial Registry (ChiCTR) for the treatment of COVID-19 with chloroquine. Chloroquine exerts direct anti-viral effects, inhibiting $\mathrm{pH}$-dependent steps of the replication of several viruses [13]. It also interferes with the glycosylation of the angiotensin-converting enzyme 2 (ACE2) receptor, preventing cells from binding to coronavirus receptors [11].Moreover, chloroquine has immunomodulatory effects, suppressing the production/release of tumor necrosis factor $\alpha(\mathrm{INF}-\alpha)$ and interleukin 6(IL-6), which mediate 
the inflammatory complications of several viral diseases [13]. The National Health Commission of China listed chloroquine as one of the therapeutic drugs of COVID-19 on February 19 [14]. But considering safety, the use of chloroquine is not recommended for those elder than sixty-five years old or who suffer from arrhythmia, chronic heart diseases and hematological system diseases. Hydroxychloroquine has a similar structure and pharmacological action to chloroquine but safer [15-19]. The anti-viral mechanism of hydroxychloroquine is unclear. However, it is speculated that it may have similar anti-viral effects to chloroquine [20-24]. Eight clinical studies of hydroxychloroquine in the treatment of COVID -19 have been registered in ChiCTR.

\section{Materials and Methods}

We obtained all data from Chengdu Public Health Clinical Medical Center, Sichuan Province, China, from February 2 to March 8, 2020. All patients were from the ICU. The diagnosis of the patients conformed to the diagnosis and treatment of the novel coronavirus pneumonia in accordance with the NHC guidelines (version 5-7). The patients were diagnosed as critically ill according to the NHC guidelines. Data sources included progress notes, laboratory examination results, vital signs, nursing records, etc.

\section{Results and Discussion}

Three elderly critically ill COVID-19 patients were treated with hydroxychloroquine in Chengdu Public Health Clinical Medical Center, China. The basic information of patients is shown in table 1. Two females and one male, the average age was $81 \pm 2.45$ years old. Three patients had cardiovascular disease, and two of them were in CDK5 stage. They had received continuous renal replacement therapy (CRRT) after admission. The average length of stay in ICU was $31 \pm 10.71$ days. Case 3 underwent endotracheal intubation due to septic shock, which significantly prolonged the course of illness and resulted in a stay in ICU for forty-three days. All three patients did not take hydroxychloroquine at the beginning of treatment. With the update of the diagnosis and treatment of COVID-19 released by the National Health Commission of China (NHC guideline), chloroquine was listed as an alternative drug in the sixth edition of the NHC guideline on February 19. Physicians began to consider chloroquine as an available anti-viral drug. Because all three patients were elderly and had underlying cardiovascular disease, the use of chloroquine may pose a greater risk, so hydroxychloroquine was chosen as a treatment. The average treatment course of all the anti-viral drugs used by three patients was $22.33 \pm 4.99$ days, among which the hydroxychloroquine was $4 \pm 0.82$ days, the dosage was $200 \mathrm{mg}$ B.i.d.

\subsection{Case 1.}

Female, seventy-nine years old, was diagnosed with COVID-19 on February 14. She was admitted to ICU for treatment due to respiratory failure. She was also a stage 5 CKD patient receiving daily CRRT. She had received anti-viral treatment for fourteen days. The virus nucleic acid testing continued to be positive before February 25.On February 27, she began to take hydroxychloroquine as $200 \mathrm{mg}$ B.i.d. On that day, it was the first time that the nucleic acid testing turned negative, but the sample was collected before the use of hydroxychloroquine (figure 1). On February 29, nucleic acid testing was still negative. Whether the use of hydroxychloroquine is related to the nucleic acid conversion in this patient cannot be determined. 


\subsection{Case 2.}

The eighty-four years old female patient was diagnosed with COVID-19 on February 3. She was admitted to ICU for treatment due to respiratory failure and required CRRT for CKD stage 5. The virus nucleic acid testing showed positive on February 26, and she began to use hydroxychloroquine $200 \mathrm{mg}$ B.i.d. in the following day. Before that, she had received the anti-viral treatment for twenty-four days. The virus nucleic acid testing was negative on February 29 (figure 1). However, at 15:10 on March 2, the patient's heart rate decreased to 49 beats per min, and blood pressure was 136/60 $\mathrm{mmHg}$, accompanied by tachypnea, doxofylline, methylprednisolone, isoproterenol was given immediately, and stopped hydroxychloroquine. At 16:37 on March 3, the patient developed severe respiratory failure with an oxygenation index below 100 and underwent endotracheal intubation. The sudden cardiac arrest occurred at 20:40 on March 3, and the electrocardiogram monitoring showed ventricular fibrillation. The rescue was successful after cardio-pulmonary resuscitation, four times of electric defibrillation, and placed a temporary pacemaker. On March 4, two days after stop taking hydroxychloroquine, the patient's nucleic acid testing turned negative.

\subsection{Case 3.}

This eighty-one years old male was identified as a suspected infector on January $23^{\text {th }}$. The nucleic acid testing of this patient was continuously negative in the early stage of the disease. However, he had an epidemiological history in Wuhan within fourteen days before admission, his wife and son were diagnosed with COVID-19, and his imaging of chest showed signs of viral infection. On January 31 he was made a definite diagnosis as COVID-19. Due to respiratory failure and septic shock, the patient was intubated and transferred to ICU for treatment. Anti-viral treatment began on January 31' and the nucleic acid testing remained positive on February 27. After eighteen days of treatment with other anti-viral drugs, hydroxychloroquine began on February 29. The administration of hydroxychloroquine was discontinued on March 2 because of concerns that Case 3 would have the same cardiac arrest as Case 2. On February 25, she was given levodopa and benserazide hydrochloride capsules $62.5 \mathrm{mg}$ T.i.d. for Parkinson's disease, the dosage was adjusted to $125 \mathrm{mg}$ T.i.d. on February 27, at the same time, pramipexole was added with a dosage of 0.125 $\mathrm{mg}$ T.i.d. On March $2^{\text {nd }}$ viral nucleic acid testing of this patient turned negative (figure 1).

The nucleic acid testing of SARS-CoV-2 in all three patients turned negative may be due to the following reasons. First of all, it occurred after the use of hydroxychloroquine, reveals hydroxychloroquine treatment may be effective. Secondly, all three patients had a long course of the disease, and the negative nucleic acid testing may be the natural course of the disease. Last, they were all treated with other anti-viral drugs for a certain time, and the effects of these drugs cannot be ignored. The cardiac arrest that occurred in Case 2 was considered for multiple reasons. Firstly, it was obviously related to the use of hydroxychloroquine, and it has been reported that hydroxychloroquine may reduce heart rate. Some in vitro studies have shown that hydroxychloroquine reduces heart rate by modulating the hyperpolarization-activated current [25].In non-active systemic lupus erythematosus(SLE) patients, the resting heart rate may significantly decrease $(11 \%)$ when the cumulative dose of hydroxychloroquine is greater than 365 $\mathrm{g}[26]$. Even the cumulative dose of hydroxychloroquine used in Case 2 was much less than $365 \mathrm{~g}$, but congestive heart failure, which may have resulted in a poor tolerance to hydroxychloroquine. In addition, Case 2 took levodopa and benserazide hydrochloride capsules and pramipexole for Parkinson's disease. Both drugs act on dopamine receptors, which can cause arrhythmias. However, cardiac arrest was still most likely to be caused by hydroxychloroquine. 

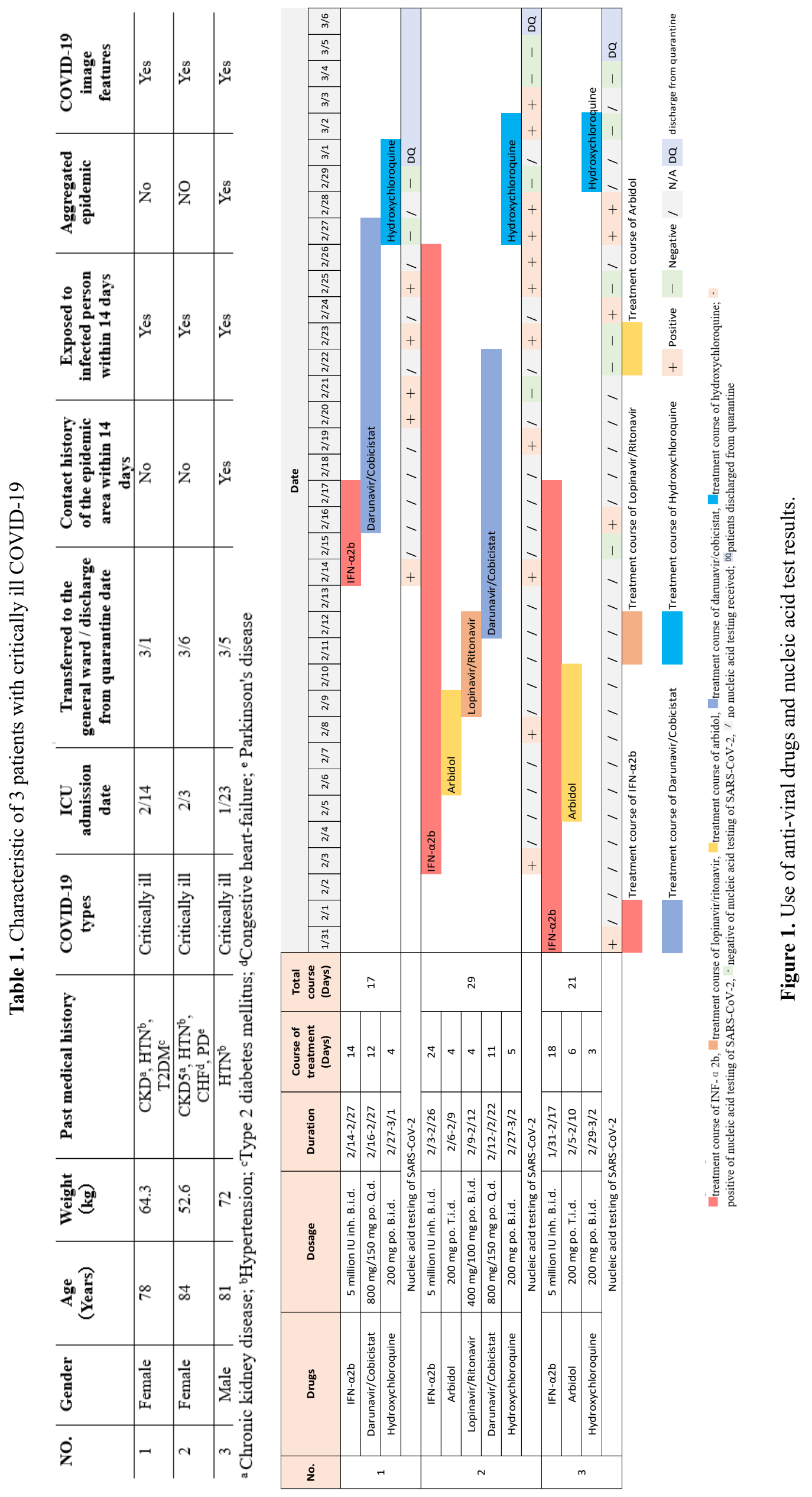


\section{Conclusions}

This report describes the therapeutic effect of hydroxychloroquine in critically ill COVID-19 patients. It suggests that hydroxychloroquine treatment may benefit nucleic acid testing of SARS-CoV-2 turning negative in critically ill COVID-19 patients. One patient developed cardiac arrest during the use of hydroxychloroquine. Although it may be related to the patient's underlying disease or other combinations, we still consider it to be an adverse reaction caused by hydroxychloroquine. Therefore, the use of hydroxychloroquine in critically ill COVID-19 patients should be very cautious, especially in the elderly or patients with poor cardiac function. Changes in heart rate should be closely monitored. To the best of our knowledge, this is the first case report on hydroxychloroquine in the treatment of critically ill COVID-19 patients. However, its effect on clinical outcomes still needs to be further verified by more high-quality studies.

\section{Funding}

This research received no external funding.

\section{Acknowledgments}

This research has no acknowledgment.

\section{Conflicts of Interest}

The authors declare no conflict of interest.

\section{References}

1. WHO Director-General's opening remarks at the media briefing on COVID-19 - March 11 2020. Available online: https://www.who.int/dg/speeches/detail/who-director-general-s-opening-remarks-at-the-mediabriefing-on-covid-19---11-march-2020 (accessed on March 11 2020)

2. Tang, W.; Cao, Z.; Han, M.; Wang, Z.; Chen, J.; Sun, W.; Wu, Y.; Xiao, W.; Liu, S.; Chen, E.; Chen, W.; Wang, X.; Yang, J.; Lin, J.; Zhao, Q.; Yan, Y.; Xie, Z.; Li, D.; Yang, Y.; Liu, L.; Qu, J.; Ning, G.; Shi, G.; Xie, Q. Hydroxychloroquine in patients with mainly mild to moderate coronavirus disease 2019: open label, randomised controlled trial. BMJ 2020,369, https://doi.org/10.1136/bmj.m1849.

3. Yang, X.; Yu, Y.; Xu, J.; Shu, H.; Xia, J.a.; Liu, H.; Wu, Y.; Zhang, L.; Yu, Z.; Fang, M.; Yu, T.; Wang, Y.; Pan, S.; Zou, X.; Yuan, S.; Shang, Y. Clinical course and outcomes of critically ill patients with SARS-CoV2 pneumonia in Wuhan, China: a single-centered, retrospective, observational study. The Lancet Respiratory Medicine 2020, 8, 475-481, https://doi.org/10.1016/S2213-2600(20)30079-5.

4. Wang, Y.; Zhang, D.; Du, G.; Du, R.; Zhao, J.; Jin, Y.; Fu, S.; Gao, L.; Cheng, Z.; Lu, Q.; Hu, Y.; Luo, G.; Wang, K.; Lu, Y.; Li, H.; Wang, S.; Ruan, S.; Yang, C.; Mei, C.; Wang, Y.; Ding, D.; Wu, F.; Tang, X.; Ye, X.; Ye, Y.; Liu, B.; Yang, J.; Yin, W.; Wang, A.; Fan, G.; Zhou, F.; Liu, Z.; Gu, X.; Xu, J.; Shang, L.; Zhang, Y.; Cao, L.; Guo, T.; Wan, Y.; Qin, H.; Jiang, Y.; Jaki, T.; Hayden, F.G.; Horby, P.W.; Cao, B.; Wang, C. Remdesivir in adults with severe COVID-19: a randomised, double-blind, placebo-controlled, multicentre trial. The Lancet 2020, 395, 1569-1578, https://doi.org/10.1016/S0140-6736(20)31022-9.

5. Runfeng, L.; Yunlong, H.; Jicheng, H.; Weiqi, P.; Qinhai, M.; Yongxia, S.; Chufang, L.; Jin, Z.; Zhenhua, J.; Haiming, J.; Kui, Z.; Shuxiang, H.; Jun, D.; Xiaobo, L.; Xiaotao, H.; Lin, W.; Nanshan, Z.; Zifeng, Y. Lianhuaqingwen exerts anti-viral and anti-inflammatory activity against novel coronavirus (SARS-CoV-2). Pharmacological Research 2020, 156, https://doi.org/10.1016/j.phrs.2020.104761.

6. Luo, E.; Zhang, D.; Luo, H.; Liu, B.; Zhao, K.; Zhao, Y.; Bian, Y.; Wang, Y. Treatment efficacy analysis of traditional Chinese medicine for novel coronavirus pneumonia (COVID-19): an empirical study from Wuhan, Hubei Province, China. Chinese Medicine 2020, 15, https://doi.org/10.1186/s13020-020-00317-x.

7. Liu, J.; Zheng, X.; Tong, Q.; Li, W.; Wang, B.; Sutter, K.; Trilling, M.; Lu, M.; Dittmer, U.; Yang, D. Overlapping and discrete aspects of the pathology and pathogenesis of the emerging human pathogenic coronaviruses SARS-CoV, MERS-CoV, and 2019-nCoV. Journal of Medical Virology 2020, 92, 491-494, https://doi.org/10.1002/jmv.25709.

8. Savarino, A.; Di Trani, L.; Donatelli, I.; Cauda, R.; Cassone, A. New insights into the anti-viral effects of 
chloroquine. The Lancet Infectious Diseases 2006, 6, 67-69, https://doi.org/10.1016/s1473-3099(06)703619.

9. Yan, Y.; Zou, Z.; Sun, Y.; Li, X.; Xu, K.-F.; Wei, Y.; Jin, N.; Jiang, C. Anti-malaria drug chloroquine is highly effective in treating avian influenza A H5N1 virus infection in an animal model. Cell Research 2013, 23, 300-302, https://doi.org/10.1038/cr.2012.165.

10. Roques, P.; Thiberville, S.-D.; Dupuis-Maguiraga, L.; Lum, F.-M.; Labadie, K.; Martinon, F.; Gras, G.; Lebon, P.; Ng, L.F.P.; De Lamballerie, X.; Le Grand, R. Paradoxical Effect of Chloroquine Treatment in Enhancing Chikungunya Virus Infection. Viruses 2018, 10, https://doi.org/10.3390/v10050268.

11. Vincent, M.J.; Bergeron, E.; Benjannet, S.; Erickson, B.R.; Rollin, P.E.; Ksiazek, T.G.; Seidah, N.G.; Nichol, S.T. Chloroquine is a potent inhibitor of SARS coronavirus infection and spread. Virology Journal 2005, 2, https://doi.org/10.1186/1743-422X-2-69.

12. Wang, M.; Cao, R.; Zhang, L.; Yang, X.; Liu, J.; Xu, M.; Shi, Z.; Hu, Z.; Zhong, W.; Xiao, G. Remdesivir and chloroquine effectively inhibit the recently emerged novel coronavirus (2019-nCoV) in vitro. Cell Research 2020, 30, 269-271, https://doi.org/10.1038/s41422-020-0282-0.

13. Savarino, A.; Boelaert, J.R.; Cassone, A.; Majori, G.; Cauda, R. Effects of chloroquine on viral infections: an old drug against today's diseases. The Lancet Infectious Diseases 2003, 3, 722-727, https://doi.org/10.1016/s1473-3099(03)00806-5.

14. National Health Commission of the People's Republic of China. Diagnosis and treatment of novel coronavirus pneumonia (Trial version 6) Available online: http://www.nhc.gov.cn/yzygj/s7653p/202002/8334a8326dd94d329df351d7da8aefc2.shtml (accessed on February 19 2020)

15. Liu, J.; Cao, R.; Xu, M.; Wang, X.; Zhang, H.; Hu, H.; Li, Y.; Hu, Z.; Zhong, W.; Wang, M. Hydroxychloroquine, a less toxic derivative of chloroquine, is effective in inhibiting SARS-CoV-2 infection in vitro. Cell Discovery 2020, 6, https://doi.org/10.1038/s41421-020-0156-0.

16. Wu, C.-L.; Chang, C.-C.; Kor, C.-T.; Yang, T.-H.; Chiu, P.-F.; Tarng, D.-C.; Hsu, C.-C. Hydroxychloroquine Use and Risk of CKD in Patients with Rheumatoid Arthritis. Clinical Journal of the American Society of Nephrology 2018, 13, 702-709, https://doi.org/10.2215/CJN.11781017.

17. Liu, D.; Li, X.; Zhang, Y.; Kwong, J.S.; Li, L.; Zhang, Y.; Xu, C.; Li, Q.; Sun, X.; Tian, H.; Li, S. Chloroquine and hydroxychloroquine are associated with reduced cardiovascular risk: a systematic review and metaanalysis. Drug design, development and therapy 2018, 12, 1685-1695, https://doi.org/10.2147/DDDT.S166893.

18. Iyer, M.; Jayaramayya, K.; Subramaniam, M.D.; Lee, S.B.; Dayem, A.A.; Cho, S.-G.; Vellingiri, B. COVID19: an update on diagnostic and therapeutic approaches. BMB Rep. 2020, 53, 191-205, https://doi.org/10.5483/BMBRep.2020.53.4.080.

19. Smit, C.; Peeters, M.Y.M.; van den Anker, J.N.; Knibbe, C.A.J. Chloroquine for SARS-CoV-2: Implications of Its Unique Pharmacokinetic and Safety Properties. Clinical Pharmacokinetics 2020, 59, 659-669, https://doi.org/10.1007/s40262-020-00891-1.

20. Singh, AK.; Singh, A.; Shaikh, A.; Singh, R.; Misra, A. Chloroquine and hydroxychloroquine in the treatment of COVID-19 with or without diabetes: A systematic search and a narrative review with a special reference to India and other developing countries. Diabetes Metab Syndr 2020, 14(3):241-246. https://doi.org/10.1016/j.dsx.2020.03.011.

21. Sun, X.; Ni, Y.; Zhang, M. Rheumotologitsts' view on the use of hydroxychloroquine to treat COVID-19. Emerging Microbes \& Infections 2020, 9, 830-832, https://doi.org/10.1080/22221751.2020.1760145.

22. Barlow, A.; Landolf, K.M.; Barlow, B.; Yeung, S.Y.A.; Heavner, J.J.; Claassen, C.W.; Heavner, M.S. Review of Emerging Pharmacotherapy for the Treatment of Coronavirus Disease 2019. Pharmacotherapy: The Journal of Human Pharmacology and Drug Therapy 2020, 40, 416-437, https://doi.org/10.1002/phar.2398.

23. Gautret, P.; Lagier, J.-C.; Parola, P.; Hoang, V.T.; Meddeb, L.; Mailhe, M.; Doudier, B.; Courjon, J.; Giordanengo, V.; Vieira, V.E.; Dupont, H.T.; Honoré, S.; Colson, P.; Chabrière, E.; La Scola, B.; Rolain, J.M.; Brouqui, P.; Raoult, D. Hydroxychloroquine and azithromycin as a treatment of COVID-19: results of an open-label non-randomized clinical trial. International Journal of Antimicrobial Agents 2020, https://doi.org/10.1016/j.ijantimicag.2020.105949.

24. Hashem, A.M.; Alghamdi, B.S.; Algaissi, A.A.; Alshehri, F.S.; Bukhari, A.; Alfaleh, M.A.; Memish, Z.A. Therapeutic use of chloroquine and hydroxychloroquine in COVID-19 and other viral infections: A narrative review. Travel Medicine and Infectious Disease 2020, https://doi.org/10.1016/j.tmaid.2020.101735.

25. Capel, R.A.; Herring, N.; Kalla, M.; Yavari, A.; Mirams, G.R.; Douglas, G.; Bub, G.; Channon, K.; Paterson, D.J.; Terrar, D.A.; Burton, R.A.B. Hydroxychloroquine reduces heart rate by modulating the hyperpolarization-activated current If: Novel electrophysiological insights and therapeutic potential. Heart Rhythm 2015, 12, 2186-2194, https://doi.org/10.1016/j.hrthm.2015.05.027.

26. Cairoli, E.; Danese, N.; Teliz, M.; Bruzzone, M.J.; Ferreira, J.; Rebella, M.; Cayota, A. Cumulative dose of hydroxychloroquine is associated with a decrease of resting heart rate in patients with systemic lupus erythematosus: a pilot study. Lupus 2015, 24, 1204-1209, https://doi.org/10.1177/0961203315580870. 